\title{
Occupant Tenability in Single Family Homes: Part Il: Impact of Door Control, Vertical Ventilation and Water Application
}

\author{
Nicholas Traina* (D) and Gavin P. Horn, Mechanical Science and Engineering, \\ University of Illinois at Urbana-Champaign, 1206 W. Green St., Urbana, \\ IL 61801, USA \\ Stephen Kerber, UL Firefighter Safety Research Institute, Underwriters \\ Laboratories, Inc., 333 Pfingsten Rd., Northbrook, IL 60062, USA \\ Dimitrios C. Kyritsis, Department of Mechanical Engineering, Khalifa \\ University of Science, Technology, and Research, Abu Dhabi, UAE \\ Gavin P. Horn, Illinois Fire Service Institute, University of Illinois at \\ Urbana-Champaign, 11 Gerty Drive, Champaign, IL 61820, USA
}

Received: 4 August 2016/Accepted: 15 February 2017

\begin{abstract}
This paper describes experimental investigations of fire service ventilation and suppression practices in full-scale residential structures, including a one-story, $112 \mathrm{~m}^{2}, 3$ bedroom, 1 bathroom house with 8 total rooms and a two-story $297 \mathrm{~m}^{2}, 4$ bedroom, 2.5 bathroom house with 12 total rooms. The two-story house featured a modern open floor plan, two-story great room and open foyer. Seventeen experiments were conducted varying fire location, ventilation locations, the size of ventilation openings and suppression techniques. The experimental series was designed to examine the impact of several different tactics on tenability: door control, vertical ventilation size, and exterior suppression. The results of these experiments examine potential occupant and firefighter tenability and provide knowledge the fire service can use to examine their vertical ventilation and exterior suppression standard operating procedures and training content. It was observed that door control performed better at controlling the thermal exposure to occupants than did fully opening the door. Additionally, the impact of increased vertical ventilation area was minimal, and only slightly reduced the thermal exposure to occupants in a few non-fire rooms. In the two-story structure, the non-fire rooms on the second floor consistently had larger thermal fractional effective rate (FER) values (approximately $2.5 \times$ the thermal risk to oocupants) than did the non-fire rooms on the first floor. Water application was also shown to reduce the thermal risk to occupants $60 \mathrm{~s}$ after water application $1 / 3$ rd the original values on second floor rooms of the two-storry structure and by at least $1 / 5$ th of the original values on the first floor rooms of both structures. Data also showed that the impact of front door ventilation on the toxic gases exposure was minimal, as the toxic gases FER actually increased after front door ventilation for several experiments. However, after vertical ventilation there was a $30 \%$ reduction in the toxic gases exposure rate in two of the one-story structure experiments.
\end{abstract}

\footnotetext{
* Correspondence should be addressed to: Nicholas Traina, E-mail: ntrain2@illinois.edu
} 
Keywords: Fire, Fire behavior, Vertical ventilation, Firefighting tactics, Tenability, Water application, Residential homes

\section{Introduction}

There is a continued tragic loss of firefighter and civilian lives during residential fires. One significant contributing factor is the lack of understanding of fire behavior in residential structures resulting from the use of ventilation as a firefighter practice on the fire ground. The changing dynamics of residential fires as a result of evolutions in home construction materials, contents, size and geometry over the past 30 years compounds our lack of understanding of the effects of ventilation on fire behavior [1]. If used properly, ventilation improves visibility and reduces the chance of flashover or back draft. On the other hand, improper ventilation can have significant impacts on tenability for occupants and, as well as potentially impacting fire spread, can lead to flashover [2].

NFPA estimates that from 2009 to 2013 [3], U.S. fire departments responded to an average of 357,000 residential fires annually. These fires caused an estimated average of 2470 civilian deaths and 12,890 civilian injuries each year. For the 2006-2009 period, there were an estimated annual average of 35,743 firefighter fire ground injuries in the U.S. [4]. Thanks in part to significant research and development by fire protection engineers that has focused on installed detection and suppression systems as well as structural fire protection, the total number of fires and fatalities due to fire have been steadily reducing. At the same time, the rate of traumatic firefighter deaths occurring outside structures, or from cardiac arrest, has declined. Unfortunately, firefighter deaths occurring inside structures has continued to climb over the past 30 years [5]. However, relatively little research has been conducted to scientifically inform the Fire Service on intervention techniques that can further reduce risk to occupants who may be trapped in structures where installed systems are not present.

Firefighters have two primary means in which they can impact the tenability of a room and contents fire for potentially trapped occupant: they can control air flow, typically through ventilation or they can absorb the energy being produced, most commonly by applying water to the fire. In firefighting, ventilation refers to the process of creating openings to remove smoke, heat and toxic gases from a burning structure and to replace them with fresh air. If used properly, ventilation improves visibility and reduces the chance of flashover or back draft. If used improperly, ventilation can cause the fire to grow in intensity and potentially endanger the lives of fire fighters who are between the fire and the ventilation opening [6].

While no known studies describe statistics for ventilation-induced fire injuries and fatalities, there are several examples of recent ventilation-impacted fires that resulted in fire fighter injuries and fatalities [7-10]. A recent NIOSH publication documents the extent of the situation: "Lives will continue to be lost unless fire departments make appropriate fundamental changes in fire-fighting tactics involving trusses. These fundamental changes include the following: Venting the roof using proper safety precautions" [11]. 
Firefighters have many tactical choices for water application, including interior attack, transitional attack, and exterior-only application of water [12-14]. The interior attack method typically involves firefighters entering the structure to apply water to the fire from a location where the fire has not yet spread, theoretically cutting off its ability to advance into the uninvolved part of the structure [12]. A transitional attack involves an initial rapid (on the order of $10 \mathrm{~s}$ ) application of water from the exterior of the structure into the fire compartment to provide the initial knockdown, which holds the fire in check while crews transition to an interior position to fully suppress the fire [13]. The exterior focused attack attempts to completely suppress the fire from the outside of the structure and is typically employed when the structural elements of the building may be compromised and/ or when no immediate occupant life safety hazard exists [14]. Each method has advantages and disadvantages, with the interior attack presenting the highest risk for exposure or collapse danger to the firefighter, while the exterior attack keeps the firefighter in a safer position but may present a challenge to accessing the seat of the fire. The transitional attack theoretically reduces the firefighters' initial exposure risk and allows the fire crews to operate an interior attack under relatively safer conditions. However, there are concerns that application of water from the exterior may cause detrimental changes to trapped occupants and cause a delay in locating potentially trapped victims.

In addition to different attack methods, firefighters also have the option to use different nozzle types, with smooth-bore and combination nozzles being the most commonly used in the US. The combination nozzle has multiple settings, from a wide-angle cone-like fog stream pattern to a narrow, relatively focused straight stream pattern. The smooth bore nozzle and straight stream pattern have the advantage of providing increased forward momentum to the water and greater penetration into the seat of the fire. The wide-angle fog stream pattern has the advantage of delivering smaller, more dispersed droplets and thus greater potential for cooling of the gases due to more rapid conversion to steam [15]. Previous work has also shown that reaching the burning fuel of the fire is a limiting factor for firefighters [16].

As previous research has shown [17], fire rooms and even some non-fire rooms can become untenable before fire service arrival, yet victims in remote rooms, particularly those behind closed doors, may still be viable. In order to affect a rescue, firefighters may need to make important decisions regarding ventilation and/or water application to the fire room. In some cases, the typical egress path for occupants may be through a common room, such as a living room or family room. Potentially viable victims may be negatively impacted if firefighters evacuate them through conditions that rapidly expose them to high heat or concentrations of toxic gases. The impact of firefighting operations on the fire environment will be quantified by examining how the different tactics influence tenability for occupants potentially trapped by the fire. Tenability can be used to mean many things, but in this study tenability will be measured using the ISO 13571 criteria for heat exposure and toxic gases [18]. This methodology has been used on many other studies to examine occupant tenability in different fire scenarios. In 2000, Purser examined the effect of ventilation on fire growth and tenability using rigs con- 
structed to simulate compartment fires [19]. The methodology has also been used to assess the risk to occupants in legacy residential housing [20], one-bedroom apartment fires [21], and basement fires [22].

The purpose of this study was to gain knowledge of the effects of vertical ventilation and the impact of different suppression techniques on occupants which may remain within the structure. The experimental results can be used to develop tactical considerations outlining firefighting ventilation and suppression practices to reduce occupant and firefighter casualties.

This study focuses on room and content fires within the living space of a residential structure. These experiments were also meant to simulate initial fire service operations by an engine company or engine and truck company arriving together in short order with approximately national average response times.

\section{Experimental Sefup}

To examine ventilation practices as well as the impact of changes in modern house geometries, two houses were constructed inside the UL large fire experimental facility in Northbrook, IL (USA). Seventeen experiments were conducted varying fire location, ventilation locations, the size of ventilation openings and suppression techniques, though this report will only focus on 6 of those scenarios (Table 1).

The experimental series was designed to examine several scenarios that were identified as gaps in current fire service knowledge of fire dynamics, ventilation and suppression [23]. These gaps include: impact of door control; impact of vertical ventilation hole size; and impact of exterior suppression. Experiments in each house were conducted 3 days apart to allow for ambient conditions inside the houses between $15^{\circ} \mathrm{C}$ and $22^{\circ} \mathrm{C}$ and below $50 \%$ relative humidity prior to ignition. While the entire study conducted 17 experiments, the focus of this paper is on the

\section{Table 1}

\section{Experimental Details (Experiment \# Refers to UL Report [23])}

\begin{tabular}{|c|c|c|c|}
\hline Experiment \# & Structure & Location of ignition & Ventilation locations \\
\hline 3 & One-story & Living room & $\begin{array}{l}\text { Front door partially open }(0.1 \mathrm{~m} \\
\quad \text { by } 2.0 \mathrm{~m})+ \text { Roof }(1.2 \mathrm{~m} \text { by } 1.2 \mathrm{~m})\end{array}$ \\
\hline 5 & One-story & Living room & $\begin{array}{l}\text { Front door }(0.8 \mathrm{~m} \text { by } 2.0 \mathrm{~m})+ \\
\quad \text { Roof }(1.2 \mathrm{~m} \text { by } 1.2 \mathrm{~m})\end{array}$ \\
\hline 7 & One-story & Living room & $\begin{array}{l}\text { Front door }(0.8 \mathrm{~m} \text { by } 2.0 \mathrm{~m})+ \\
\quad \text { Roof }(1.2 \mathrm{~m} \text { by } 2.4 \mathrm{~m})\end{array}$ \\
\hline 4 & Two-story & Family room & $\begin{array}{l}\text { Front door partially open }(0.1 \mathrm{~m} \text { by } \\
2.0 \mathrm{~m})+\operatorname{Roof}(1.2 \mathrm{~m} \text { by } 1.2 \mathrm{~m})\end{array}$ \\
\hline 6 & Two-story & Family room & $\begin{array}{l}\text { Front door }(0.8 \mathrm{~m} \text { by } 2.0 \mathrm{~m})+ \\
\quad \text { Roof }(1.2 \mathrm{~m} \text { by } 1.2 \mathrm{~m})\end{array}$ \\
\hline 8 & Two-story & Family room & $\begin{array}{l}\text { Front door }(0.8 \mathrm{~m} \text { by } 2.0 \mathrm{~m})+ \\
\quad \text { Roof }(1.2 \mathrm{~m} \text { by } 2.4 \mathrm{~m})\end{array}$ \\
\hline
\end{tabular}


six experiments outlined in Table 1 and the effectiveness of the different ventilation tactics used.

\subsection{One-Story Structure}

Four of the experiments took place in the one-story structure. The structure was designed to be representative of a home constructed in the mid-twentieth century. The one-story structure had an area of $112 \mathrm{~m}^{2}$, with $2.4 \mathrm{~m}$ ceilings and included 3 bedrooms, 1 bathroom and 8 total rooms (Figure 1). The home was wood framed, lined with two layers of gypsum board (base layer $16 \mathrm{~mm}$, surface layer $13 \mathrm{~mm}$ ) to protect the structure and allow for multiple experiments. All of the windows were closed with removable inserts so that window opening could be controlled at the time specified for each experiment. A roof ventilation system was created above the living room to allow for remote roof ventilation. Hinged openings were used to simulate a roof cut being "pulled open" and a section of ceiling was able to be removed simulating the ceiling being "pushed" through from above to ventilate the fire in the living space.

\subsection{Two-Story Structure}

The two-story structure had an area of $297 \mathrm{~m}^{2}$; with 4 bedrooms, 2.5 bathrooms and 12 total rooms (Figures 2, 3). The structure incorporated features common in early twenty-first century construction, such as an open floor plan, two-story great

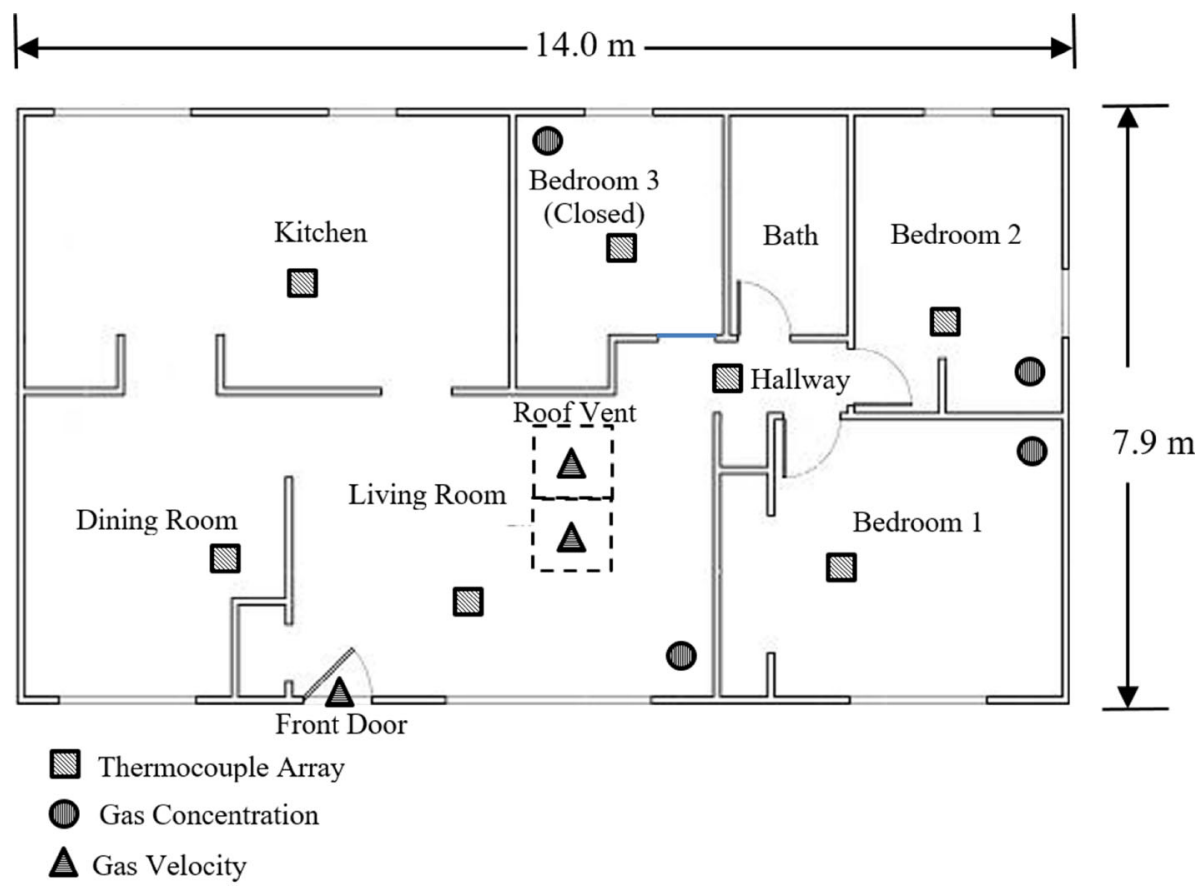

Figure 1. One-story house floor plan with instrument locations. 
room, open foyer, and half landing stairs. The home was also a wood framed structure lined with two layers of gypsum board (Base layer $16 \mathrm{~mm}$, Surface layer $13 \mathrm{~mm}$ ). The windows had similar removable inserts. A roof ventilation system was created above the family room to allow for remote roof ventilation. Hinged sections of roof could be opened to simulate a roof cut being completed. This section did not have an interior ceiling to be "pushed" because this section of the roof above the great room was simulated to be a cathedral style ceiling, i.e. the interior volume of the compartment extended to the ceiling of the second floor, with a height of $5.2 \mathrm{~m}$, having no void below the flat roof. The area of the family room that extended to the ceiling of the second floor is indicated by the dotted line encompassing the family room in Figure 2.

\subsection{Fuel Load}

The living room in the one-story house and the family room in the two-story house were furnished similarly with two sofas, television stand, television, end table, coffee table, chair, ottoman, two pictures, lamp with shade, and two curtains The floor was covered with polyurethane foam padding and polyester carpet. The fuel loading was approximately $29 \mathrm{~kg} / \mathrm{m}^{2}$. Pictures of the fuel load for each structure can be found in Figure 4. Additional rooms in the house were fully furnished with typical residential bedroom, dining room, and kitchen furnishings. However, these materials did not contribute to the fuel load involved in the fires of interest to this manuscript.
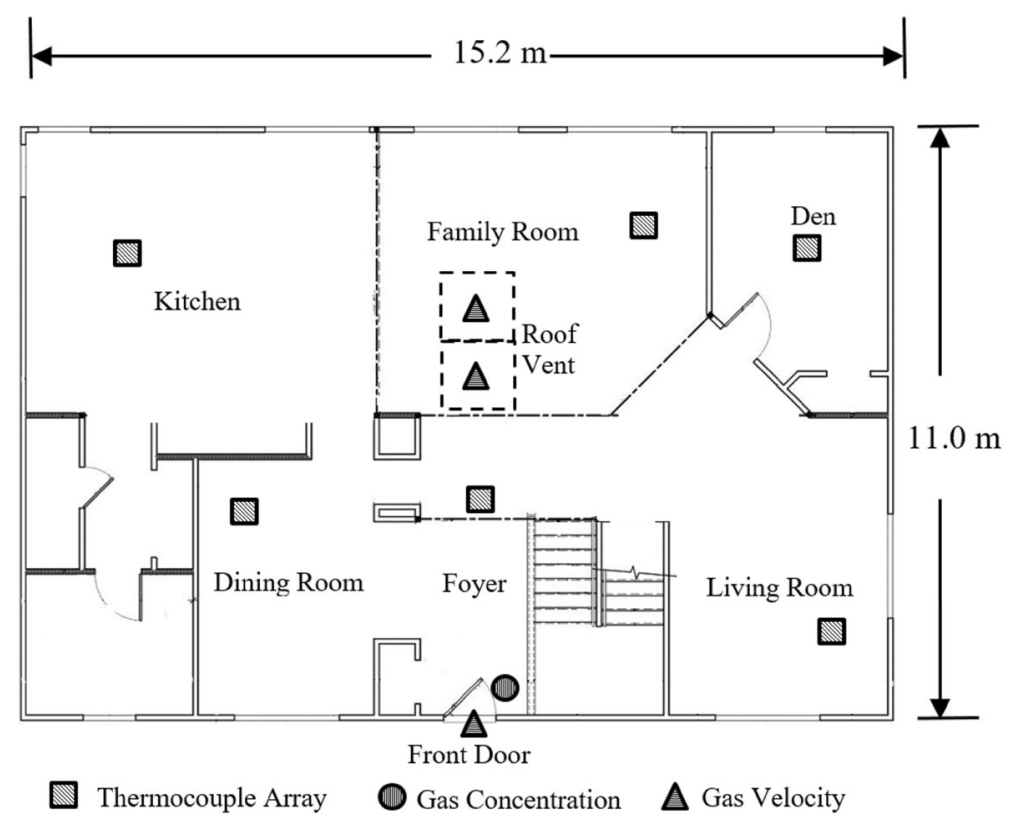

Figure 2. Two-story house first floor plan with instrument locations. 


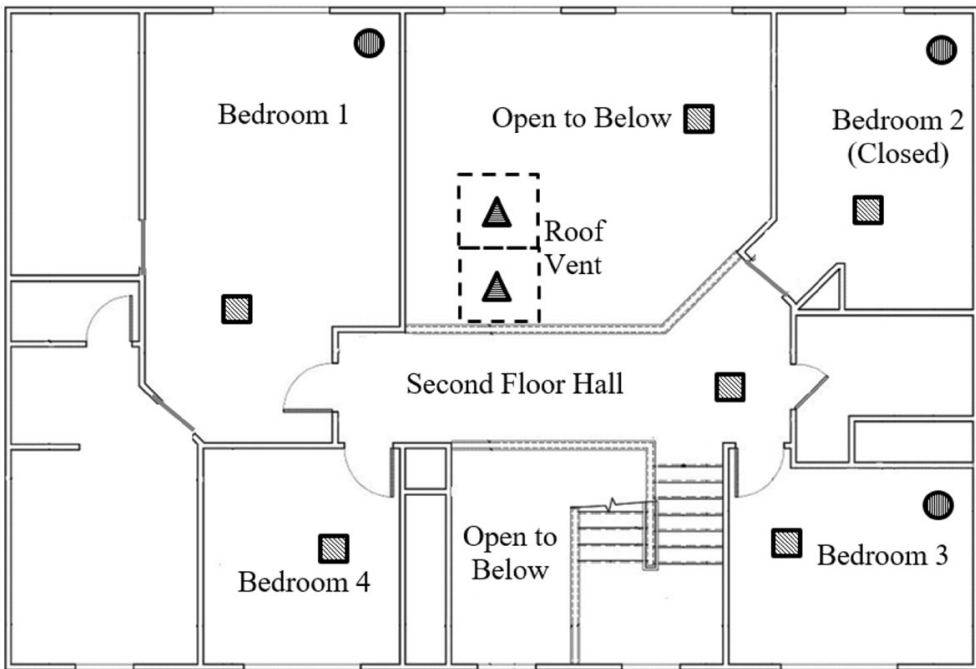

Thermocouple Array

(1) Gas Concentration

A Gas Velocity

Figure 3. Two-story house second floor plan with instrument locations.
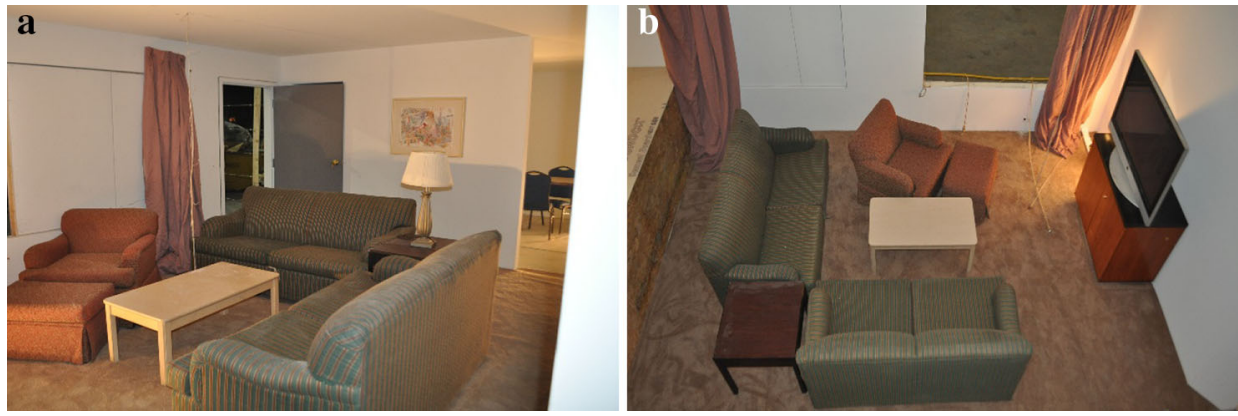

Figure 4. (a) One-story living room fuel load (picture from hallway of one-story). (b) Two-story family room fuel load (picture from roof vent down into family room).

In order to characterize the living/family room fuel load, the fuels were placed in a $5.5 \mathrm{~m}$ wide by $4.0 \mathrm{~m}$ deep room by $2.4 \mathrm{~m}$ high room underneath an oxygen consumption calorimeter. The room had a $3.1 \mathrm{~m}$ wide by $2.1 \mathrm{~m}$ tall opening on the front wall. The measured peak heat release rate of the fuel load was $8.8 \mathrm{MW}$ [23].

\subsection{Instrumentation}

The measurements taken during the experiments included gas temperature, gas velocity, gas concentrations, and video recording. Gas temperature was measured 
with bare-bead, type $\mathrm{K}$ thermocouples, with a $0.5 \mathrm{~mm}$ nominal diameter. Thermocouple array locations are shown in Figures 1, 2, and 3. Thermocouples were located in the living room and hallway in the one-story house and foyer and second floor hallway in the two-story house. Each location had an array of thermocouples with measurement locations of $0.03,0.3,0.6,0.9,1.2,1.5,1.8$ and $2.1 \mathrm{~m}$ below the ceiling. Thermocouple arrays were also located in the dining room, kitchen, den and bedrooms had measurement locations of $0.3,0.9,1.5$, and $2.1 \mathrm{~m}$ below the ceiling. The family room had thermocouple locations every $0.3 \mathrm{~m}$ below the ceiling down to the floor. The uncertainty in type $\mathrm{K}$ thermocouple measurements is less than $1-2 \%$ of the measured value for temperatures up to $1250 \mathrm{~K}$ [24].

Gas velocity was measured utilizing differential pressure transducers connected to bidirectional velocity probes, located in the front doorway and the roof ventilation opening (Figures 1, 2, and 3). There were five probes on the vertical centerline of each doorway located at $0.3 \mathrm{~m}$ from the top of the doorway, the center of the doorway, and $0.3 \mathrm{~m}$ from the bottom of the doorway. Thermocouples were co-located with the bidirectional probes to complete the gas velocity measurement.

Gas concentrations of oxygen, carbon monoxide, and carbon dioxide were measured (Ultramat 23 NDIR; Siemens) at $0.9 \mathrm{~m}$ from the floor adjacent to the front door and in bedrooms 1, 2 and 3 for both houses. Gas concentration measurements after water flow into the structure are not reliable may not be accurate due to the effect of moisture on the gas measurement equipment. The uncertainty of the measured concentration is $1 \%$ of the maximum concentration measurement. The maximum concentration measurements were $1 \%$ for $\mathrm{CO}$ and $10 \%$ for $\mathrm{CO}_{2}$. When this occurs, values are estimated at the saturation level for both gasses, resulting in some FED values that are conservative estimates, and subsequently increasing the uncertainty and bias of the FED values (as the reported values will be smaller than the actual exposure). All samples are collected at $1 \mathrm{~Hz}$.

\subsection{Experimental Methodology}

All of the experiments started with the exterior doors and windows closed, the roof vents closed, and all of the interior doors open except for Bedroom 3 in the one-story and Bedroom 2 in the two-story structure. For the six experiments that will be the focus of this manuscript, the fires were ignited on a sofa in the living room (one-story) or family room (two-story). Additionally, it should be noted that none of the fires spread from the compartment of origin to any additional rooms.

The fire was allowed to progress in the closed structures until ventilation operations were simulated. The one-story house was ventilated at 8 min after ignition, and two-story house vented $10 \mathrm{~min}$ after ignition. This was timeline determined based on three factors; time to achieve ventilation limited conditions in the house, potential response and intervention times of the fire service, and window failure times from previous window failure experiments [23]. The additional 2 min for the larger structure ensured ventilation-limited conditions were achieved, as the available oxygen in the larger volume required more time to be consumed. 
On the fireground, vertical and horizontal ventilation are performed at different time scales. There is an obvious difference between ventilating a glass window with a tool from the ground versus climbing to the roof and creating a ventilation hole through the roof membrane. Therefore, the timing of the vertical ventilation openings (which were created above the fire room) was done based on interior conditions and not a specific time. The criterion chosen was a temperature of $200^{\circ} \mathrm{C}$ at a height of $0.9 \mathrm{~m}$ in the area that a firefighting crew could be operating. This approach was chosen because a crew operating in that area could request vertical ventilation to improve the conditions. In addition, front door ventilation was conducted either fully open $(80 \mathrm{~cm})$ or partially open $(10 \mathrm{~cm}$ wide, but since the door swings open the actual width of opening was $46 \mathrm{~cm}$ from door jamb to corner of the door to allow for hose movement). The ventilation operation with only $10 \mathrm{~cm}$ width of front door ventilation is representative of a firefighting tactic that may be used to limit the inflow of oxygen to the seat of the fire, while also still allowing for hose movement in the structure. After ventilation, the fire was allowed to grow until the maximum burning rate occurred, as determined by the temperatures measured in the fire room, observation of exterior conditions, and monitoring of the internal video. A hose stream was flowed in through the front door (which, if opened only $10 \mathrm{~cm}$ wide during fire development, was fully opened for suppression), with the firefighter on one knee and directing the hose stream to the ceiling of the fire room and to the burning fuel for both the one- and twostory structures.

The stream of water $(45 \mathrm{~mm}$ line with a combination nozzle creating a flow of approximately $380 \mathrm{lpm}$ ) was directed into the front door for approximately $15 \mathrm{~s}$. The $15 \mathrm{~s}$ water application was used to approximate the typical timing of a "transitional attack" tactic and not meant to completely suppress the fire. The potential for regrowth of the fire after this short application was an important aspect of this tactic to be studied. Two types of flow patterns were utilized during the experiments: straight stream and fog stream. During straight stream application, the nozzle was adjusted to a tightly focused pattern and directed into the structure with the guidance of putting water on what was burning, so the nozzle was not held stationary. During the fog stream application, the nozzle was adjusted to create an approximate $30^{\circ}$ fog pattern with a broken stream and directed into the structure with the intent to move the nozzle as necessary to extinguish the visible fire. The experiment was terminated at least 1 min after application of the hose stream, and suppression was completed by the firefighting crew.

As an example, Figure 5 shows a typical time-temperature evolution (collected at a height of $0.9 \mathrm{~m}$ ) in the one-story structure (Experiment 3 ). This figure shows the growth of the fire along with some key benchmark times of the experimental procedure. In every experiment, the procedure followed these important steps: (1) firefighters arrive 8-10 min after ignition, (2) first firefighter intervention is front door ventilation and lasts for 1.5-4 min, (3) second intervention is vertical ventilation and lasts until flashover, (4) third intervention is water application after which the fire is allowed to persist for another minute prior ro the experiment being brought to an end. 


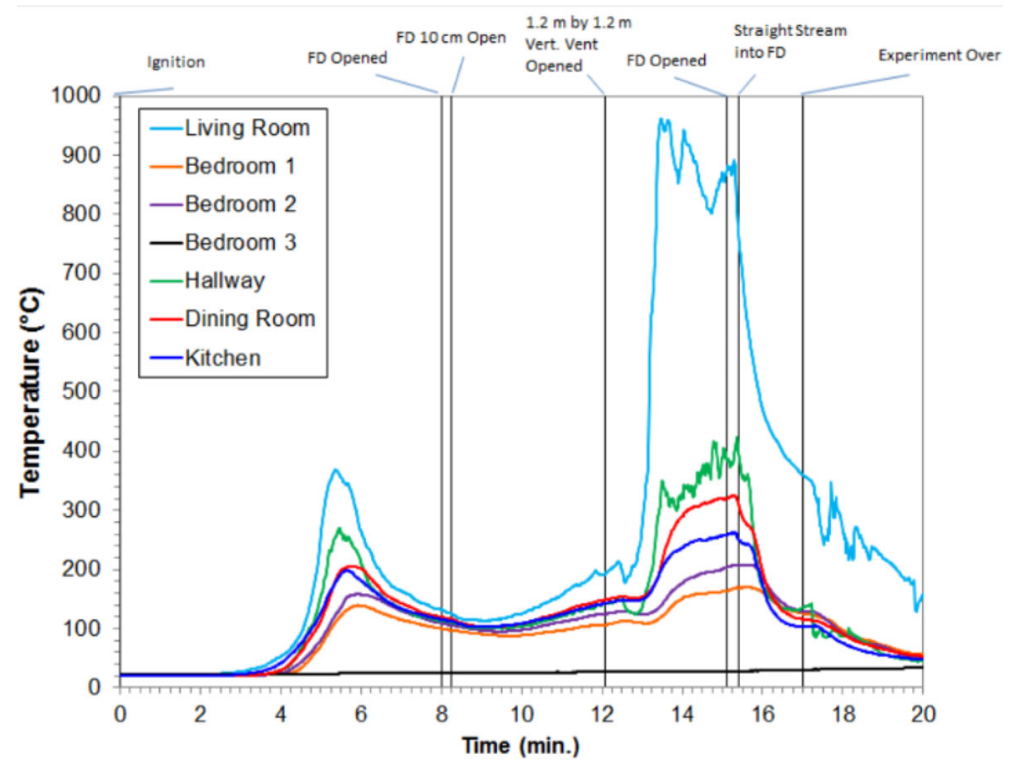

\section{Figure 5. Temperafures at $0.9 \mathrm{~m}$ above the floor in every room of Experiment 3, which had the front door only $10 \mathrm{~cm}$ open as the initial ventilation operation.}

For comparison, Figure 6 shows the time-temperature curve from an experiment with the front door fully opened $(0.8 \mathrm{~m})$, showing the more rapid transition to flashover after firefighter ventilation with the larger opening for make-up air.

\subsection{Fractional Effective Rate Methodology}

Occupant tenability, which is the survivability of occupants in the fire environment, is a primary concern for any firefighting operation. Two measures of occupant tenability were used during these experiments; temperature and gas concentration based on the fractional effective dose (FED) methodology that is outlined in ISO 13571 [18]. This methodology allows for the calculation of time to incapacitation based on an accumulated exposure to either heat or toxic gases and provides specified thresholds that are commonly utilized to estimate risk. Based on a lognormal distribution, FED $=0.3$ is the criterion used to determine the time for incapacitation of susceptible people $(11 \%$ of the population, includes young children, elderly, and/or unhealthy occupants) and FED $=1.0$ is the value at which exposure would be considered untenable for $50 \%$ of the population.

FEDs were calculated at an elevation of $0.9 \mathrm{~m}$ above the floor for both houses, representative of a person lying or crawling on the floor. Any individual lying in bed or attempting to evacuate a structure while standing are likely to be exposed to a higher temperature and likely larger gas concentrations. The equations used to calculate the FED values at each time are given by Equations 1, 2a and 3a. 


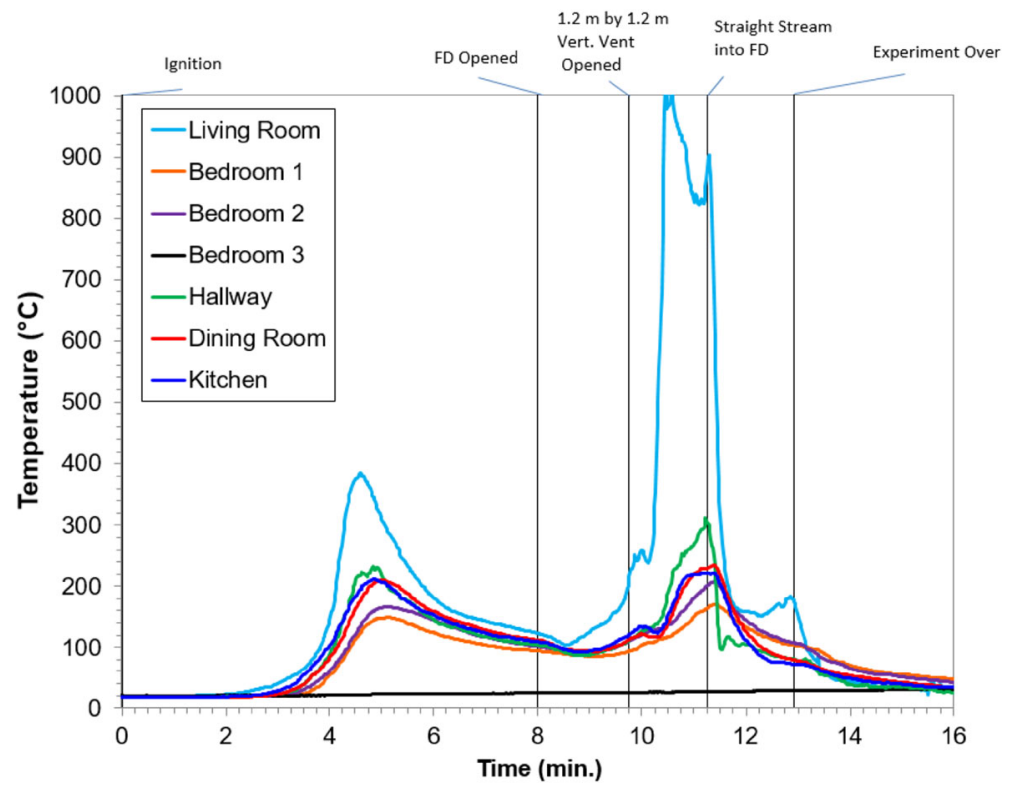

Figure 6. Temperatures at $0.9 \mathrm{~m}$ above the floor in every room of Experiment 5, which had the front door fully opened $(0.8 \mathrm{~m})$ as the initial ventilation operation.

$$
\begin{aligned}
& v_{\mathrm{CO}_{2}}=\exp \left(\frac{\varphi_{\mathrm{CO}_{2}}}{5}\right) \\
& F E D_{\mathrm{CO}}=\sum\left[\frac{\varphi_{\mathrm{CO}}}{3.5} v_{\mathrm{CO}_{2}} \cdot \Delta t\right] \\
& F E D_{\text {heat }}=\sum\left[\left(\frac{T^{3.61}}{4.1 \times 10^{8}}\right) \cdot \Delta t\right]
\end{aligned}
$$

where $v_{\mathrm{CO}_{2}}$ is a frequency factor to account for the increased rate of breathing due to carbon dioxide, $\varphi_{\mathrm{CO}_{2}}$ and $\varphi_{\mathrm{CO}}$ are the mole fractions (\%) of carbon dioxide and carbon monoxide, $\mathrm{T}$ is the temperature near the occupant $\left({ }^{\circ} \mathrm{C}\right)$, and $\Delta t$ is the time increment of the measurements made in the experiments in minutes. According to ISO 13571, the uncertainty in Equation 2a is $\pm 20 \%$ and the uncertainty in Equation $3 \mathrm{a}$ is $\pm 35 \%$. Equation 3 only applies for temperatures greater than $120^{\circ} \mathrm{C}$.

Traditionally, risk estimates are based on the entire timeframe of an exposure. For the scenarios of interest here, we are studying transient exposures that may be experienced while firefighters are attempting to affect rescue for a potentially trapped occupant with the goal of informing fire service tactics that may minimize the 
additional exposure risk for those who are being rescued. To better understand the instantaneous exposure, we will utilize the fractional effective rate (FER), which is the accumulation of FED with respect to time (units of FED/s).

$$
\begin{aligned}
& F E R_{C O}=\frac{\varphi_{C O}}{3.5} \cdot v_{C O_{2}} \cdot \frac{1}{60} \\
& F E R_{\text {heat }}=\left(\frac{T^{3.61}}{4.1 \times 10^{8}}\right) \cdot \frac{1}{60}
\end{aligned}
$$

As an example, Figure 7 shows the Fractional Effective Rate (FER) as a function of time for Experiment 3 in the living room at $0.9 \mathrm{~m}$ above the floor for both $\mathrm{CO}$ and heat exposure. If, for instance, an occupant was rescued from a closed room at $8 \mathrm{~min}$ and then exits the structure at $12 \mathrm{~min}$, then the total exposure to the occupant would be the area under the curve. Over the span of those $4 \mathrm{~min}$, the accumulated exposure would be FED $=1.92$. In the fire room, thermal exposure typically accumulates faster than gas exposure for most of the burn scenarios unless ventilation limited conditions are present. Through the initial growth of the fire, $\mathrm{CO}$ exposure rates are very slow until approximately $5 \mathrm{~min}$, when the temperatures begin to decrease and the burning rate reduces. Exposures based on gas levels would then accumulate faster near the occupants until vertical ventilation is provided after which the fire rapidly transitions to flashover. It should also be noted that the flat portion of the $\mathrm{CO}$ exposure near $6 \mathrm{~min}$ and near $14 \mathrm{~min}$ is due to the saturation of the gas sampling equipment.

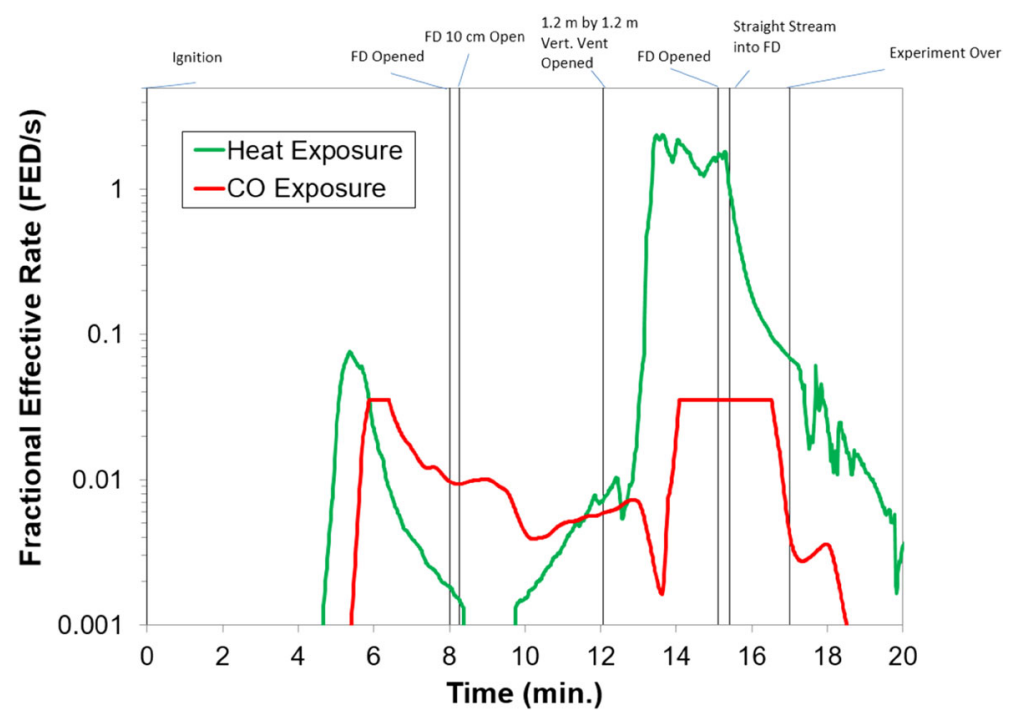

Figure 7. Fractional effective rate (FED/s) in fire room for Experiment 3 for both heat and toxic gases exposure. 
The focus of this paper is on the effect of different firefighting tactics on the fire environment. However, for the experiments studied in this paper, the FED exposure prior to firefighter arrival is important for fire department decision making and is shown in Table 2. The exposure prior to fire department intervention can be large, especially in bedrooms with open doors in the one-story structure. These data show the inherent variability in fire development and potential occupant exposure, even for identical conditions prior to initial ventilation. While the best effort was made to compare similar experiments, and control as many variables as possible, fires themselves significantly contribute to the variability in the data and further research is needed to quantify the sources of variability in fire growth and response. For a full discussion on tenability prior to fire department arrival, see Part I [25]. The major takeaway though is that outside of closed bedrooms, occupants have likely received a lethal dose from the toxic gases. However, the occupants trapped behind closed doors are still facing tenable conditions and could be rescued.

\section{Results and Discussion}

As previous research has shown, occupants may have received minimal exposure to heat and toxic gases prior to firefighter intervention if behind closed doors. While they may have some level of safety when protection is in place, fireground actions which can reduce the risk for egress through common areas such as family rooms and living rooms can improve the likelihood of safe rescue. On the other hand, in areas of the structure away from the fire, they may have a significant exposure to fireground gases, such that immediate rescue and medical attention is necessary. Fireground actions that can reduce exposure to these gases and increase the rate at which firefighters can access these victims is critical. Fire Service intervention, through ventilation or water application, can impact the ability to safely evacuate these surviving individuals. We included data from both non-fire rooms, where surviving victims may be impacted by the fire service even if they stay in place, as well as fire rooms, through which victims may attempt self-rescue or be evacuated by firefighters.

\subsection{The Effect of Firefighter Ventilation Tactics on Occupant Tenability}

3.1.1. Fire Room This section will examine the impact of ventilation tactics on occupant tenability within the fire environment. Figures $8 \mathrm{a}, 8 \mathrm{~b}$ show the FER for heat exposure as a function of time after front door ventilation, up until vertical ventilation takes place. Vertical vents were opened when the fire room temperature at $0.9 \mathrm{~m}$ exceeded $200^{\circ} \mathrm{C}$. Thus for Experiment 3 this was approximately $4 \mathrm{~min}$ after the door was opened (See Figure 5), but between $1.5 \mathrm{~min}$ and $2 \mathrm{~min}$ for the $0.8 \mathrm{~m}$ door opening cases. The blue solid lines are for $10 \mathrm{~cm}$ door opening with $1.2 \times 1.2 \mathrm{~m}$ vent, the red dashed lines are $0.8 \mathrm{~m}$ door opening with $1.2 \times 1.2 \mathrm{~m}$ vertical vent, and the black dotted line is for $0.8 \mathrm{~m}$ door opening with $1.2 \times 2.4 \mathrm{~m}$ vertical vent. The scenarios where the front door was fully opened, tenability rapidly reduced about $50 \mathrm{~s}$ after opening of the front door for both the 


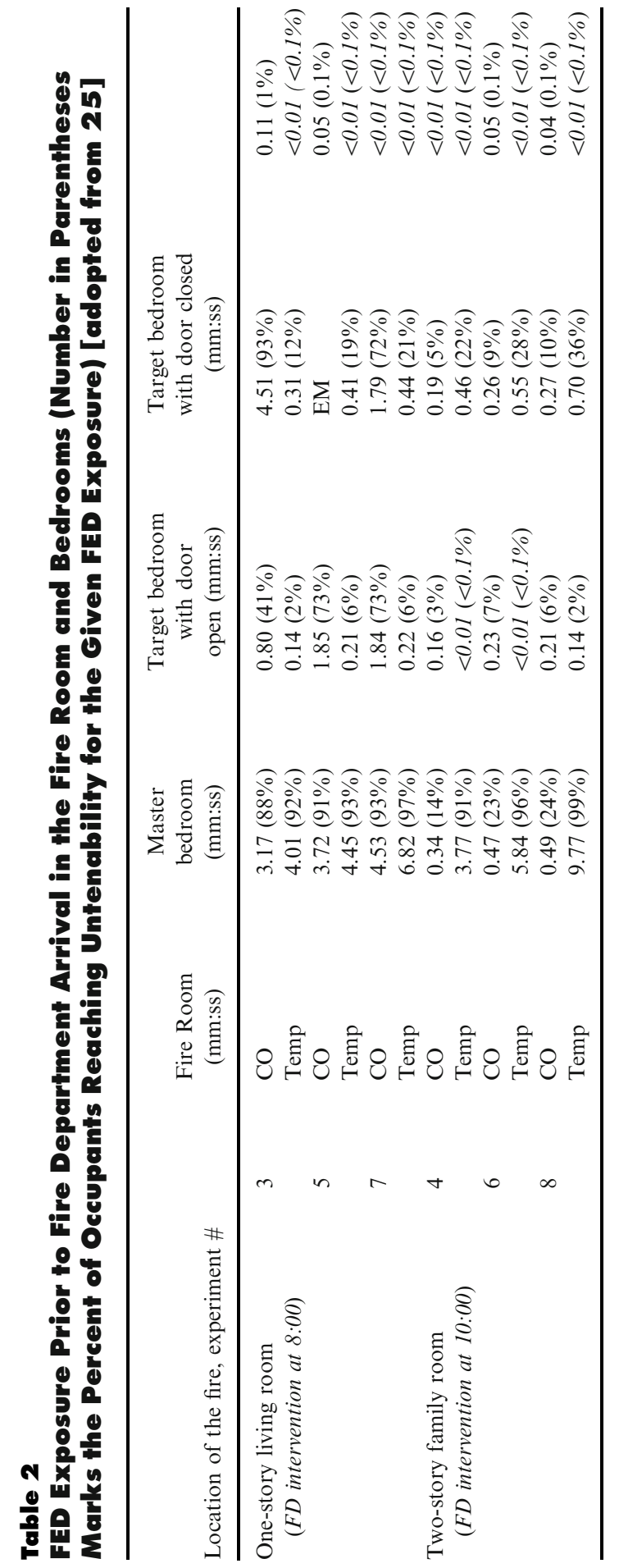


one-story $(\operatorname{Exp} 5,7)$ and two-story $(\operatorname{Exp} 6,8)$ structures. However, with the front door only partially opened (Exp 3 and 4), the time to when FER increased in the fire room was dramatically delayed. In the one story structure, FER increased to 0.005 at about $200 \mathrm{~s}$ compared to $80 \mathrm{~s}$ with the door fully open. For the two story structure, there was no measurable increase in FER with the door control compared to a rapid increase from about 0.01 to 0.03 in about $60 \mathrm{~s}$ with the door fully opened. While FER does begin to increase due to the change in ventilation conditions, the accumulation of FED for potentially trapped victims to be removed through fire room is relatively small in the one story structure if rescue can be affected rapidly.

Figures 9a, b show the heat exposure FER for the fire rooms as a function of time after vertical ventilation for the one-story and two-story structure. Vertical ventilation resulted in the FER reaching values greater than $1 \mathrm{FED} / \mathrm{s}$ in 5 of the 6 experiments, which is very rapid when considering that FED $=1$ corresponds to $50 \%$ of occupants reaching untenability. The vertical ventilation clearly resulted in significant growth in the fire. Occupants that are evacuated through rooms under these conditions will be rapidly impacted by the thermal conditions, even if they were behind closed doors and relatively unexposed prior to fire service intervention. The experiments with the front door only $10 \mathrm{~cm}$ open delayed the increase in fractional effective rate by $30 \mathrm{~s}$ in the one-story structure, and for the entirety of the experiment for the two-story structure. However, in both structures, there were negligible differences in the changes in FER in the fire room for the different vertical ventilation areas. For these scenarios, after vertical ventilation a unidirectional exit flow path is created with exhaust through the vertical vent and make up air provided by the open front door. Even with the make up air limited to the relatively small front door opening, enough fresh air is allowed to enter the fire room to reach flashover conditions. The increase in incoming air flow after vertical ventilation is seen in Figure 10, which shows the velocity at the centerline (height of $1.05 \mathrm{~m}$ ) of the door (negative velocities represent incoming air). In particular, note the increase in incoming air at the onset of vertical ventilation, as the neutral plane of the doorway clearly rises. With both the $1.4 \mathrm{~m}^{2}$ and the $2.9 \mathrm{~m}^{2}$ vertical vent openings, thermal conditions in the fire room rapidly deteriorated. The larger opening for make-up air by the fully opened front door was sufficient to achieve flashover for the one-story structure. However, the reduction in makeup air based by the partially closed door significantly impacted the fire behavior. In fact, in the two-story structure, flashover was not achieved, possibly due to the high ceilings and reduced compartmentation in the fire room.

3.1.2. Non-fire Rooms Outside of the fire room, the heat exposure and temperatures in the non-fire room do not significantly change after front door ventilation. In fact, there were no significant differences in the heat exposure for non-fire rooms for any of these experiments after front door ventilation and before vertical ventilation.

However, after vertical ventilation, the thermal conditions in the non-fire rooms did begin to deteriorate in both the one-story (Figure 11) and two-story (Figure $12 \mathrm{a}, \mathrm{b})$ structures. In the one-story structure, vertical ventilation area had little 


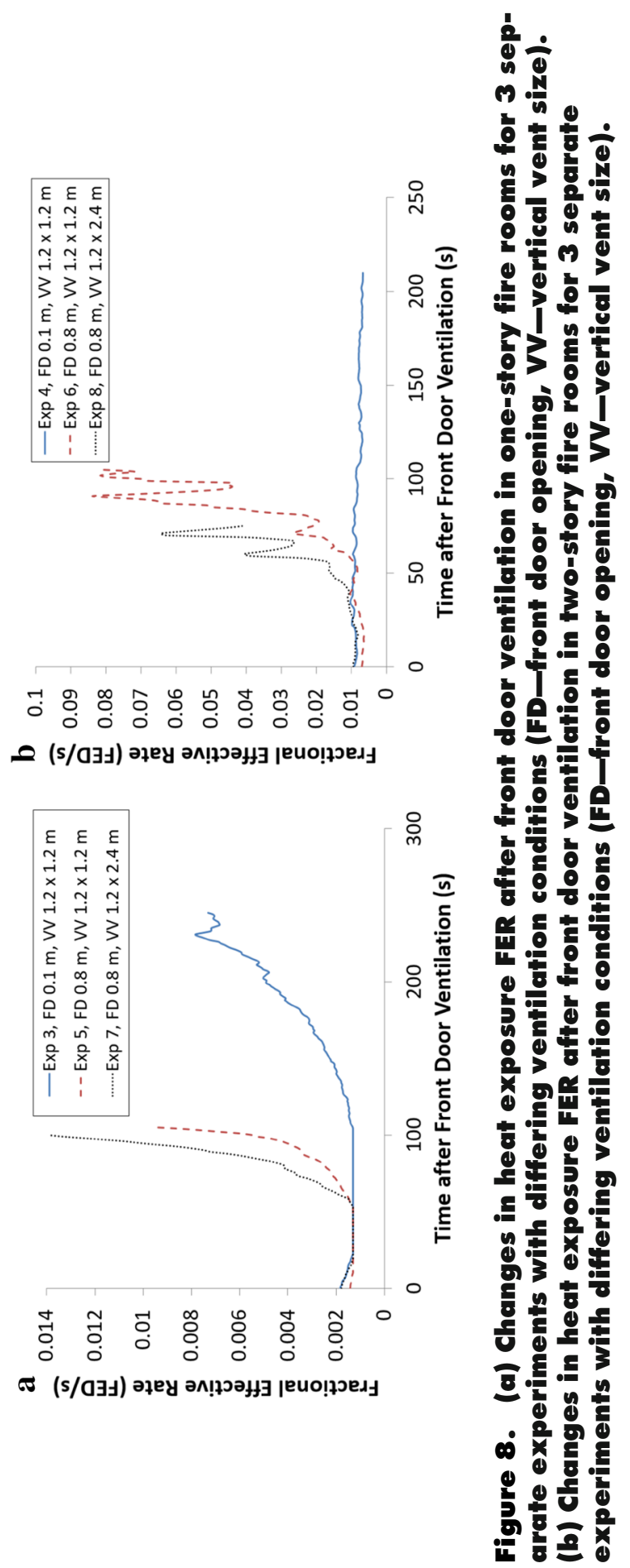




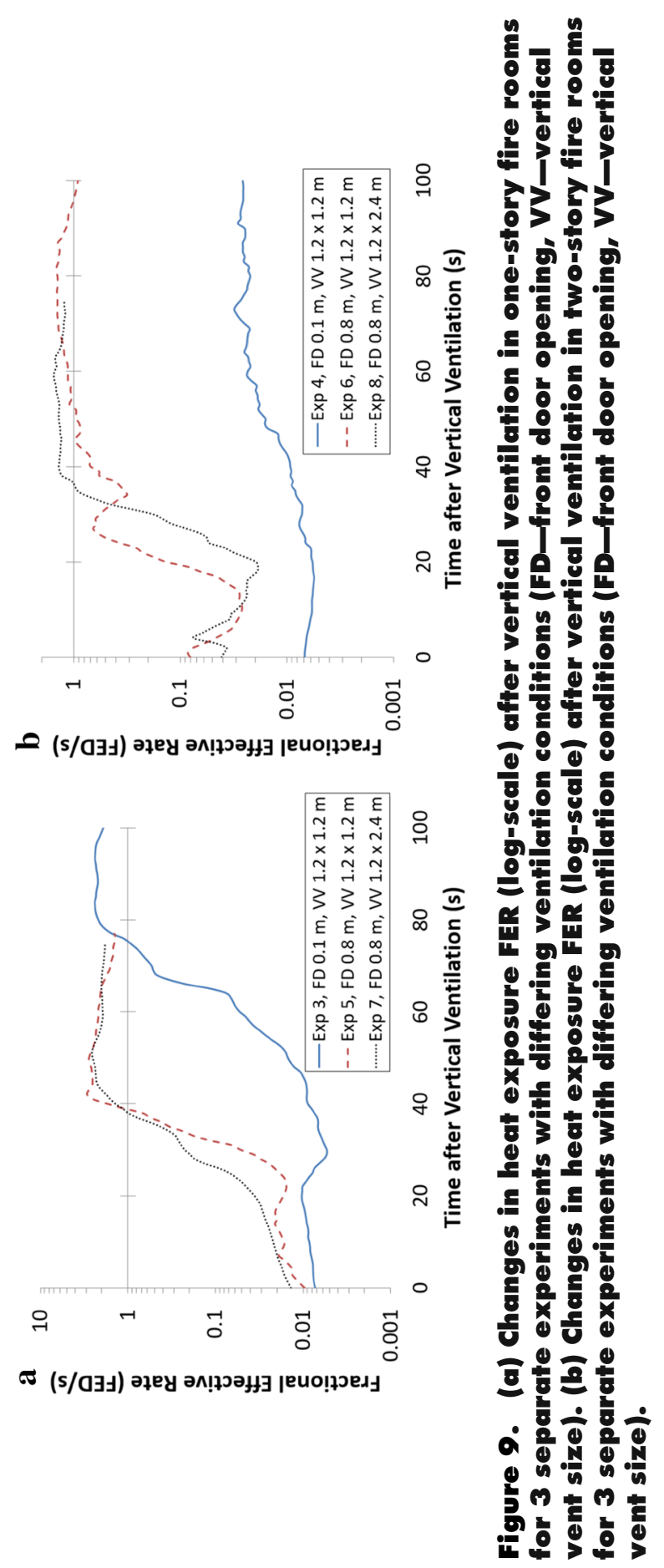




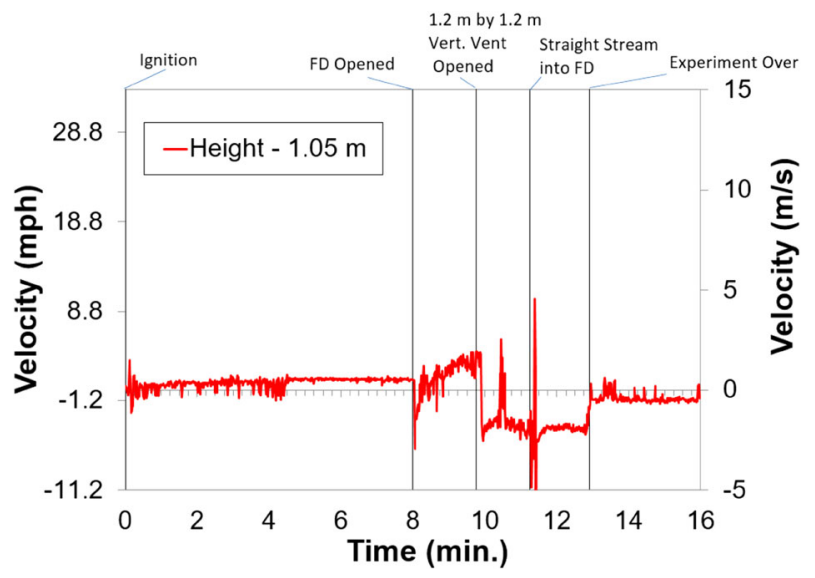

Figure 10. Velocity at the centerline of the doorway at the $1.05 \mathrm{~m}$ height for Experiment 5. Negative velocities indicate gases flowing into the structure. Positive velocities indicate gases flowing out of the structure.

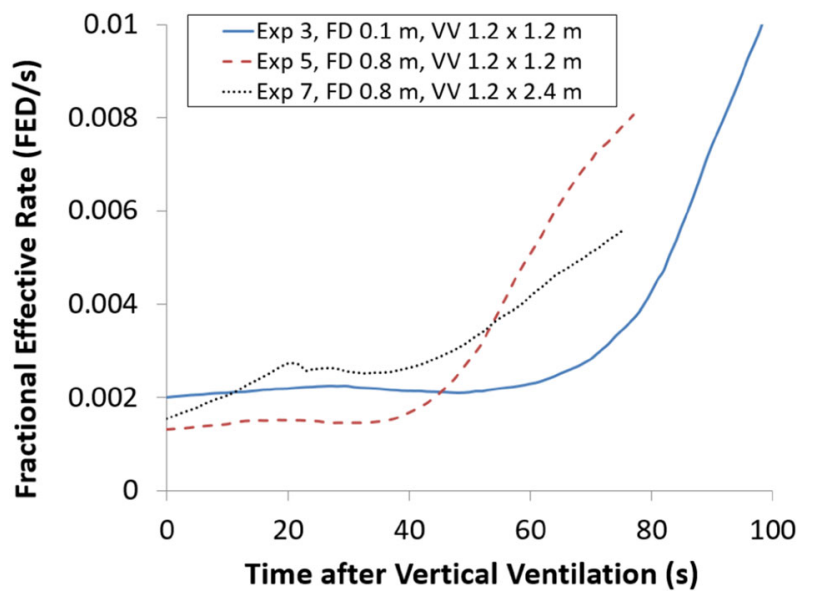

Figure 11. Changes in heat exposure FER after vertical ventilation in one-story non-fire rooms for 3 separate experiments with differing ventilation conditions (FD-front door opening, VV-vertical vent size).

effect on the heat exposure FER for the non-fire rooms (Exp 5 and 7). However, reducing the inlet flow by controlling the front door opening (Exp 3) again delayed the onset of increasing FER values by more than $30 \mathrm{~s}$.

In the two-story structure, non-fire rooms on the second floor consistently have higher FER values than the first floor non-fire rooms. This is due to the buoyant nature of the hot gases, which leads to higher temperatures in the second floor 
rooms than the first floor rooms. Limiting the influx of air by opening the front door only $10 \mathrm{~cm}$ impacted the rate of change of the FER values, as it took more than $180 \mathrm{~s}$ after vertical ventilation to reach an average FER greater than 0.015 $\mathrm{FED} / \mathrm{s}$ for the second floor rooms compared to $45 \mathrm{~s}$ after vertical ventilation for the fully open front door (with same vertical vent area). In these scenarios, the total vertical ventilation area does appear to have an impact on non-fire room thermal conditions. The time to reach an average FER of $0.015 \mathrm{FED} / \mathrm{s}$ on the second floor rooms for the $1.44 \mathrm{~m}^{2}$ vertical ventilation scenario was less than $40 \mathrm{~s}$. However, for the experiment with $2.9 \mathrm{~m}^{2}$ vertical ventilation, it was more than $75 \mathrm{~s}$ before reaching an average FER value greater than $0.015 \mathrm{FED} / \mathrm{s}$. The lower FER values for the larger ventilation area experiment suggests that in the twostory structure, the increase in the exhaust of hot gases could be large enough to meaningfully reduce the spread of hot gases to the non-fire rooms. Relatively speaking, controlling the front door only $10 \mathrm{~cm}$ open was more effective than the increased vertical ventilation area in limiting the risk from heat exposure (and operationally more rapidly employed, while likely reducing the risk to the firefighters).

In addition to heat exposure for potentially trapped occupants, the effect of carbon monoxide exposure on tenability must also be considered. Figures 13a, b show the changes in FER values for the master bedroom (bedroom 1 in one-story and bedroom 3 in two-story) after front door ventilation for the one-story and two-story structures, respectively. In the one-story structure, the toxic gases FER values are already greater (in some cases by more than $2.5 \times$ ) in bedroom 1 than the highest heat exposure FER values after vertical ventilation. In the two-story structure, however, the toxic gases FER values are actually relatively low compared to the largest FER heat exposure values observed after different ventilation tactics (approximately $1 / 10$ th of the heat exposure values on the second floor nonfire rooms). Importantly, it appears that front door ventilation tactics have little impact on the toxic gases FER values. Opening the front door alone does not provide significant relief from gas exposure for potentially trapped victims.

Likewise, changes in CO FER values after vertical ventilation are largely independent of both the vertical ventilation opening size and inlet air opening size (Figure 14a, b). There were two experiments that saw increases in the CO FER values but both of those increases occurred because the ventilation tactic led to quickly to flashover and sustained flashover for long enough to fill the structure with carbon monoxide before water was applied to the structure. If the other experiments had waited longer to apply water it is expected that similar observations would be made for all of the experiments. It is clear that prior to flashover, the changes in CO FER values in the structure are minimal compared with the changes witnessed for heat exposure FER values $(5-50 \%$ change in the toxic gases FER values compared to $500+\%$ increase for heat exposure FER values after front door ventilations).

In the specific scenarios studied here, vertical ventilation alone does not provide significant improvements in life safety for trapped occupants. The $60-80 \mathrm{~s}$ of relatively small changes after front door ventilation and similar times prior to rapid increase in thermal conditions after vertical ventilation can provide a critical win- 


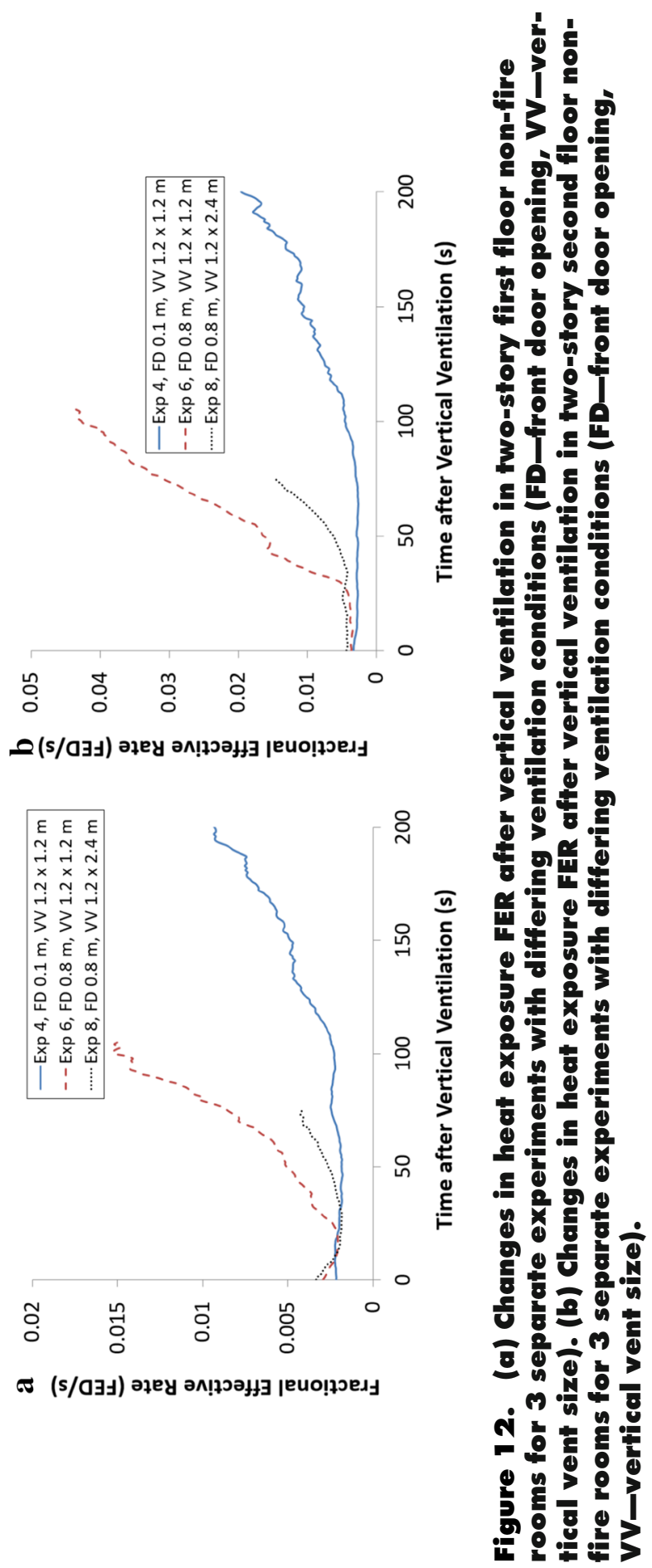




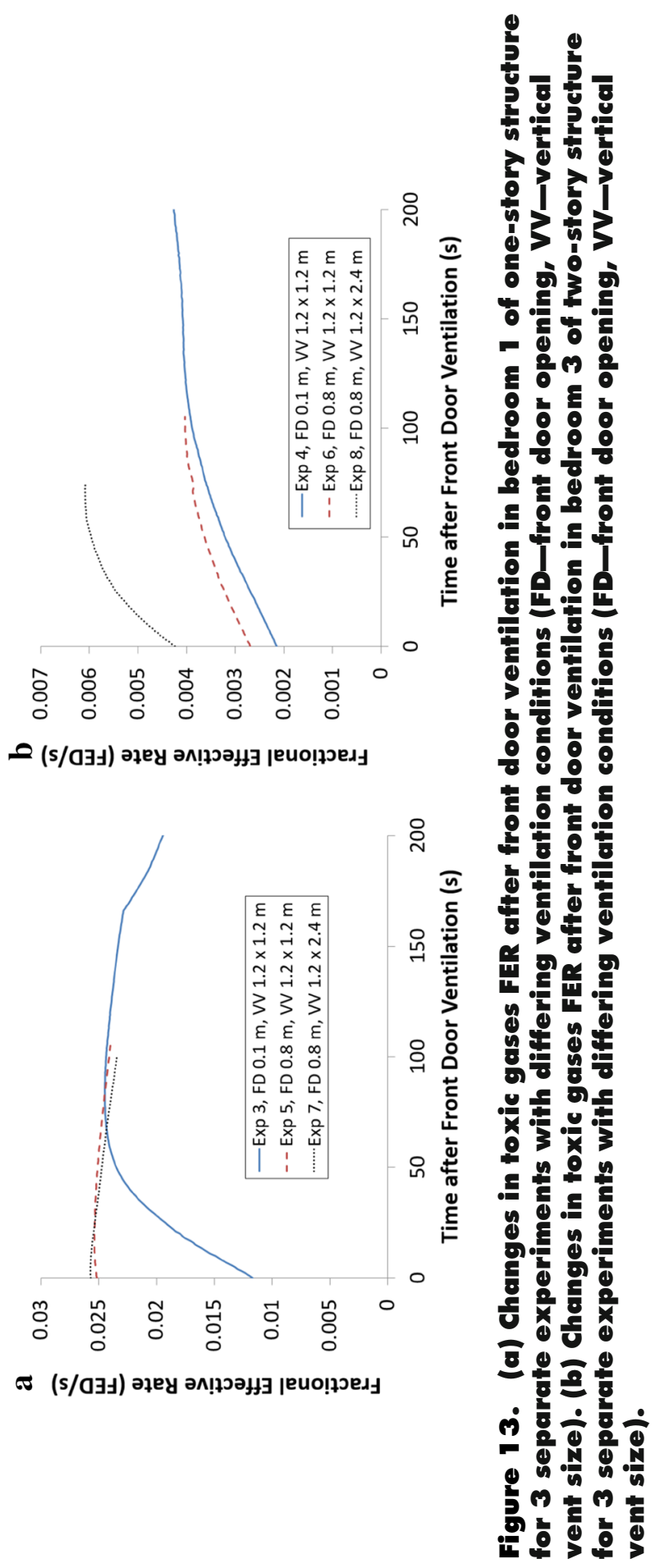




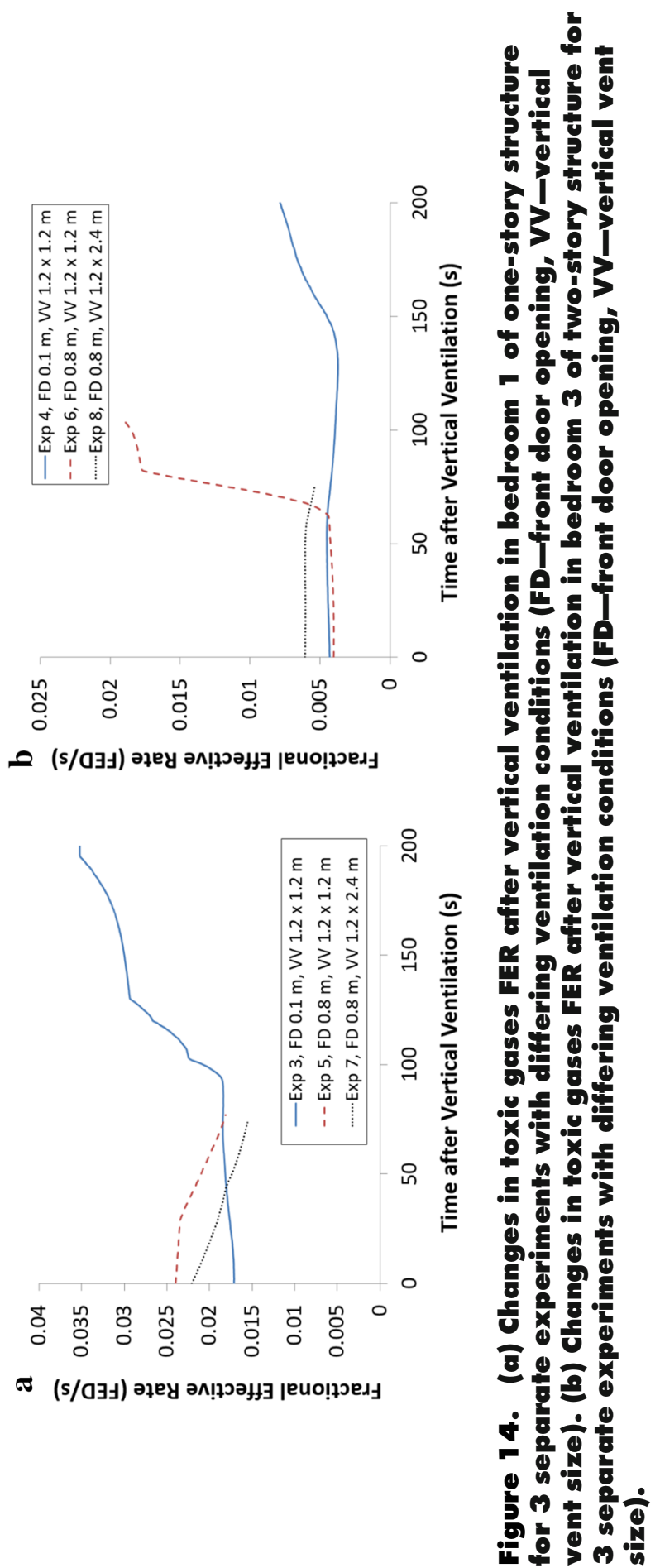


dow for finding and rescuing victims. This timeframe also provides the firefighters with a critical opportunity to put water on the fire prior to reaching flashover conditions.

\subsection{Effect of Water Application on Tenability in the Fire Environment}

The second tool that firefighters have to control fireground conditions is application of water. Unfortunately, the gas concentration measurement technique utilized in this study is not reliable in the presence of water, so the effect of water application on gas exposure could not be assessed. However, the impact of water application on heat exposure tenability can be characterized. Figures 15 and 16 show the average change in FER values after water application for the one-story and two-story structure. Water application results in a significant reduction of the heat exposure FER values, especially in the fire room. The FER values change from greater than $1 \mathrm{FED} / \mathrm{s}$ to lower than $0.01 \mathrm{FED} / \mathrm{s}$ in approximately $20 \mathrm{~s}$. The changes in the non-fire rooms is less drastic but still substantial in both structures. The average FER prior to water application in the one-story structure was greater than $0.01 \mathrm{FED} / \mathrm{s}$, however approximately $60 \mathrm{~s}$ after water application, the average was reduced to $0.0015 \mathrm{FED} / \mathrm{s}$, an $85 \%$ reduction in heat exposure risk to occupants. In the two-story structure, the water application reduced the risk significantly for both the first floor rooms $(0.01 \mathrm{FED} / \mathrm{s}$ to $0.0013 \mathrm{FED} / \mathrm{s})$ and the second floor rooms $(0.03 \mathrm{FED} / \mathrm{s}$ to $0.01 \mathrm{FED} / \mathrm{s})$. However, the second floor rooms have substantially higher FER throughout the scenarios due to the convective nature of the gases. Interestingly, after approximately $15 \mathrm{~s}$ past suppression, the temperatures in the second floor rooms are greater $0.9 \mathrm{~m}$ above the floor than are the corresponding temperatures in the fire room. Irregardless of impact on toxic gas exposure, this reduction in temperatures throughout the structure highlights the importance of water application prior to evacuating potentially trapped occupants through common rooms.

Figure 15 also shows the maximum and minimum FER values for fire and nonfire rooms in the one-story structure. This data highlights the variability in risk exposure from fire to fire and even room to room in the same fire. As can be seen, the difference in FER values varies by up to an order of magnitude even for nonfire rooms, and in the case of fire rooms can vary by more than 2 orders of magnitude at the same point in time after water application. In the cases where substantial decreases in FER were observed (FER $<0.01 \mathrm{FED} / \mathrm{s})$, the water application had been able to successfully suppress much of the fire. However, in the cases where the FER values remain greater than $0.1 \mathrm{FED} / \mathrm{s}$ the water application was successful in cooling the hot gases and suppressing part of the fire, but residual heat and potentially small pockets of fire still remained after water application. Even in the cases where the fire room would still expose occupants to large FER, there was a reduction in the FER values in the non-fire rooms. It is important that, after initial exterior water application, the firefighter rapidly transition to the interior in order to locate any remaining hot spots and fully suppress the fire even if there is no life safety hazard in the structure. Importantly, in every one of these scenarios, temperatures in all fire and non-fire rooms never increased as a 


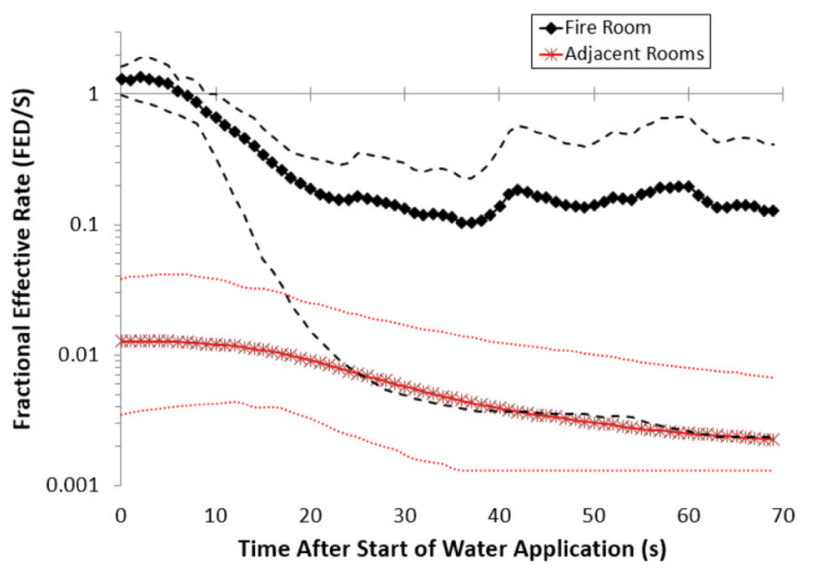

Figure 15. Average FER values at $0.9 \mathrm{~m}$ high in the fire room and the non-fire rooms after water application in the one-story structure (Exp 3, 5, 7). Solid lines with markers represent the average FER of the dafa set. Dashed lines represent the max and min of the fire room data set. Dotfed lines represent the max and min of the adjacent room data set.

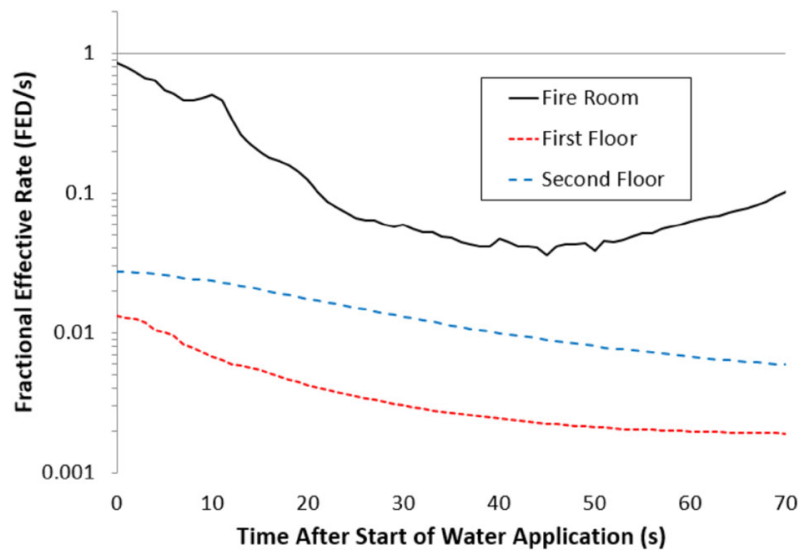

Figure 16. Average FER values after water application at $0.9 \mathrm{~m}$ high in the fire room, first floor rooms, and second floor rooms the twostory structure (Exp 4, 6, 8). data shows the FER value averaged for the 3 experiments and for all the rooms in the data series.

result of water application. In other words, none of these scenarios, where water was introduced from the exterior, resulted in fire or hot gasses being displaced from the fire room to a non-fire compartment. In each case, the risk to the occupant during egress reduced in both the fire and non-fire rooms. 
The temperature reduction in non-fire rooms due to a straight stream applied directly to the fuel source can drastically improve the thermal tenability for occupants in non-fire rooms in the timeframe applicable to a firefighter's transitional attack tactics. In order to visualize the information in a different manner, we can plot the change in non-fire room temperature as function of the compartment temperature immediately prior to water application (Figure 17). The data presented in Figure 17 comes from every straight stream water application during the 17 experiment study. When water is applied with a straight stream setting temperatures are always reduced in the non-fire rooms (positive temperature reduction), with a larger effect in the rooms with higher initial temperature (typically those closer to the fire room). There are several interesting analyses that can be performed with this data. For example, on the plot is an overlay of the criteria for firefighter thermal tenability threshold of $260^{\circ} \mathrm{C}$ [26]. All of the data points left of the vertical line correspond to non-fire rooms that were tenable for firefighters before water application $(n=67)$. Data points between the vertical tenability line and inclined tenability line represent compartments where temperature was initially larger than the temperature threshold, but, $60 \mathrm{~s}$ after water application, the temperature was below the temperature threshold $(n=25)$. Data points to the right of the respective inclined tenability lines represent rooms where the temperature remained above the temperature threshold both before and $60 \mathrm{~s}$ after water application $(\mathrm{n}=0)$. Temperatures in every non-fire room $60 \mathrm{~s}$ after straight stream water application were below the $260^{\circ} \mathrm{C}$ threshold for firefighters. Therefore, applying water from the exterior was able to improve tenability conditions in

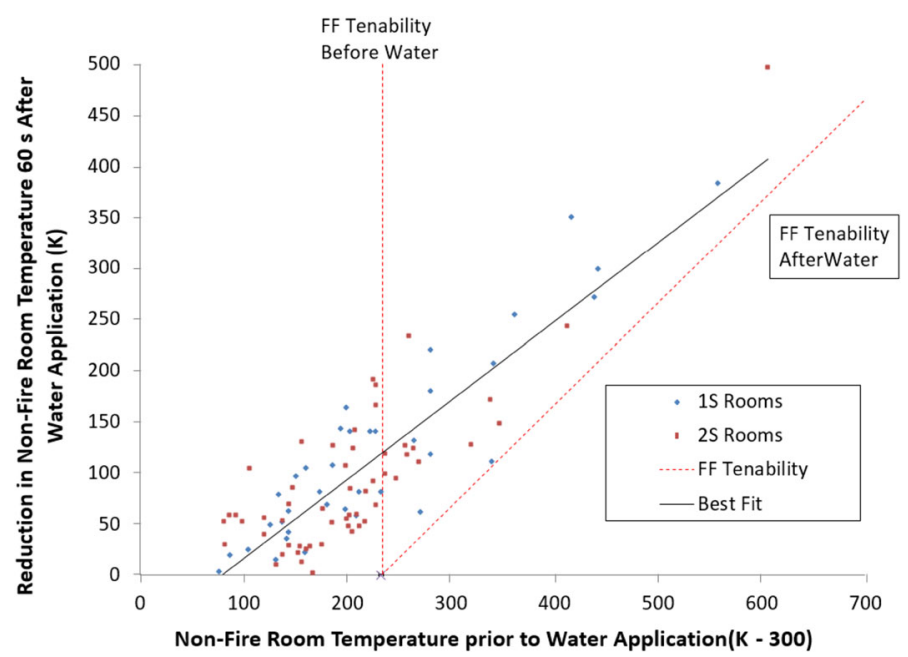

Figure 17. Effect of water application on firefighter tenability. The vertical dotfed line shows the fire fighter tenability criteria prior to water application, and the slanfed dotfed line shows the firefighter tenability criferia $60 \mathrm{~s}$ after water application. The solid line is the best fit line for the data set. 
the non-fire rooms and hallways and reduce the risk for firefighters searching the structure.

While this manuscript focuses mainly on the scenarios that were conducted with straight stream nozzle settings, a few experiments were also conducted using fog stream suppression. Performing an analysis similar to Figure 17 on this data set showed that the temperature $60 \mathrm{~s}$ after fog stream water application was above the thermal tenability threshold for firefighters for 3 out of the 22 non-fire room and hallway observations. Both nozzles were operated at the same nominal flow rate, so this difference in effect can largely be explained by the time dependence of the cooling effects of the two stream types.

To characterize the effectiveness of water application in the fire room with respect to a range of non-fire room temperatures, we can analyze Figure 17 in a slightly different manner. By calculating a best fit line to this data set (black solid line in Figure 17) at various different times after water application, we can begin to characterize the time rate of change of thermal conditions in these rooms as well as compare different suppression techniques.

Figures 18 and 19 shows the time dependence of cooling for the straight stream and fog stream data at $0 \mathrm{~s}, 10 \mathrm{~s}, 30 \mathrm{~s}$, and $60 \mathrm{~s}$ after water application has ended. For the straight stream nozzle, while no temperatures were seen to increase, there is no measureable effect in the non-fire rooms immediately after the water stops flowing. However, cooling increases consistently with time after water application. With the fog stream application, cooling in non-fire rooms occurs even before water application ends and achieves the largest reduction in temperatures $30 \mathrm{~s}$ after water application. Importantly, the slope of this best fit line changes throughout the time-course of cooling and the effect becomes less pronounced in non-fire rooms with a higher start temperature (i.e. closer to the fire room). The

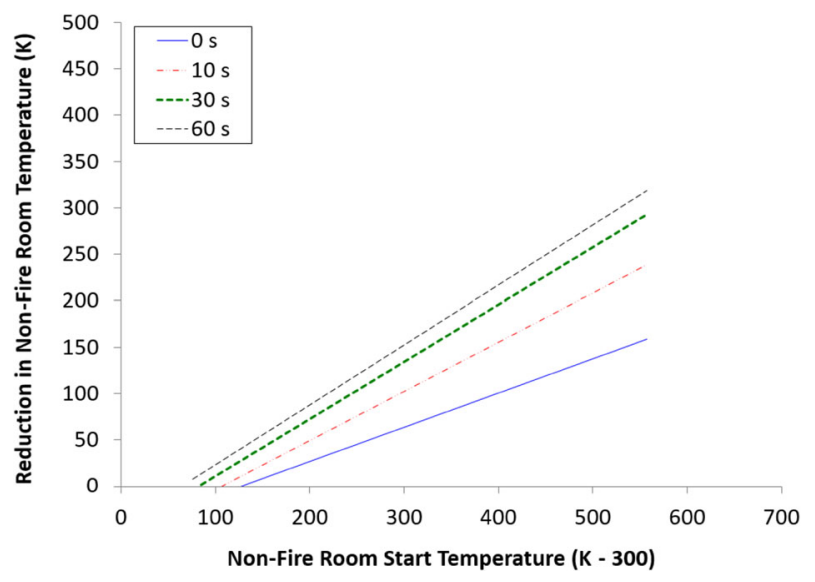

Figure 18. Temperature reductions in non-fire rooms for straight stream applications at $0 \mathrm{~s}$ (blve, solid), $10 \mathrm{~s}$ (red, long dash), $30 \mathrm{~s}$ (green, dotted), and 60 s (black, short dash) after water application (Color figure online). 


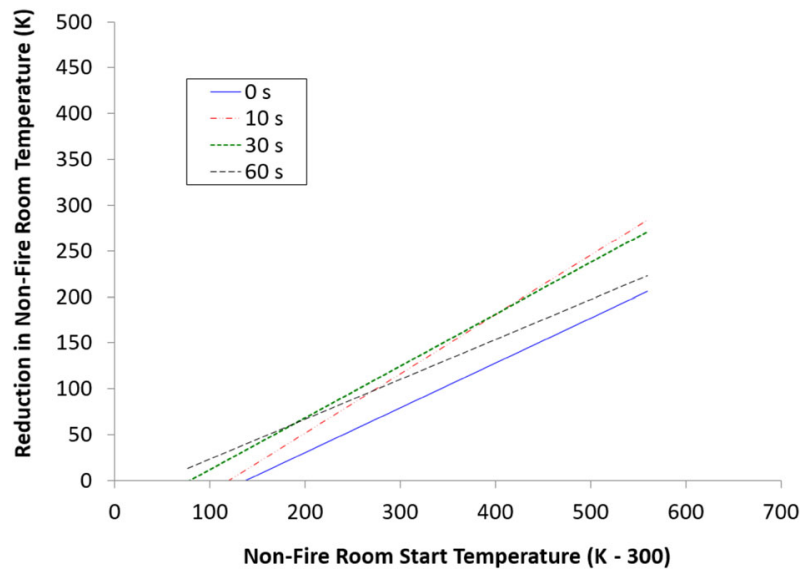

Figure 19. Temperature reductions in non-fire rooms for fog stream applications at 0 s (blue, solid), 10 s (red, long dash), 30 s (green, dotfed), and $60 \mathrm{~s}$ (black, short dash) after water application (Color figure online).

fog stream produces smaller, more dispersed droplet sizes that are capable of more effectively cooling the hot gases, as has been shown in previous literature [27]. However, the straight stream water focuses the momentum of the water to allow increased penetration through the hot gases to reach the fuel sources and directly cool the burning material. Therefore, the fog stream accomplishes quick cooling of the compartments due to cooling of the gases (and potentially contraction of the hot upper gas layer), but since the source of the heat is not as significantly impacted, the temperatures in the structure begin to recover quicker than for straight stream water applications.

\subsection{Firefighter Tactical Considerations}

One of the major takeaways from this research is the importance of limiting the air supply to the fire for ventilation limited fires. The experiments where the door was opened to allow access and then closed the width of a hoseline slowed the growth of the fire, which maintained lower interior temperatures and better gas concentrations than if the door were opened completely. This allows for fire department intervention while keeping the fire at a lower heat release rate, which makes it easier to extinguish.

There was not a ventilation hole size used in these experiments that slowed the growth of the fire. All vertical ventilation holes created flashover and fully developed fire conditions more quickly. Once water was applied to the fire, however, the larger the hole was, and the closer it was to the fire, allowed more products of combustion to exhaust out of the structure, causing temperatures to decrease and visibility to improve. Ventilating over the fire is a viable option if your fire attack is coordinated. 
Water was applied to the fire from the exterior during every experiment, in some experiments through the doorway and some through the window. In almost all of the experiments, tenability was improved everywhere in both structures with the application of water into the structure, even in locations downstream of the fire in the flow path. The data demonstrated the potential benefits of softening the target prior to making entry into the structure; the inability to push fire, as fire was never close to being forced from one room to another with a hose stream; and the benefits of applying water to the seat of the fire in a large open volume.

The fire dynamics of home fires are complex and challenging for the fire service. Ventilation is paramount to understand for safe and effective execution of the mission of the fire service to protect life and property. Vertical ventilation is especially important because it requires being positioned above the fire and can have a fast impact on interior fire conditions. This research study developed experimental fire data to demonstrate fire behavior resulting from varied ignition locations and ventilation opening locations in legacy residential structures compared to modern residential structures. This data will be disseminated to provide education and guidance to the fire service in proper use of ventilation as a firefighting tactic that will result in reduction of the risk of firefighter injury and death associated with improper use of ventilation and to better understand the relationship between ventilation and suppression operations.

\section{Summary and Conclusions}

The impact of important firefighter interventions; front door ventilation, vertical ventilation, and water application, were quantified by analyzing the rate of change in heat-exposure- and CO-FED over time (FER) in a one-story and two-story residential structure. It was observed that in all cases, venting the structure resulted in FER values that either did not improve occupant tenability or, at worst case, significantly reduced occupant tenability. However, the tactic of controlling the opening of the front door to $10 \mathrm{~cm}$ open was shown to delay the time for increasing FER values and resulted in less rapid growth of the fire for both the one-story and two-story structure. In contrast, for the experiments where the front door was fully open upon vertical ventilation, the FER values increased from less than 0.01 $\mathrm{FED} / \mathrm{s}$ to greater than $1 \mathrm{FED} / \mathrm{s}$ in the fire room in less than a minute after vertical ventilation.

Two different vertical ventilation sizes were used in the experiments, $1.4 \mathrm{~m}^{2}$ and $2.9 \mathrm{~m}^{2}$. The only observed difference between the two vertical ventilation areas was in the two-story structure, where the non-fire rooms had slightly less rapid growth of the FER values for the larger ventilation area.

After ventilation of the structure, the exposure to toxic gases remained a hazard to occupants with typical FER values larger than $0.01 \mathrm{FED} / \mathrm{s}$ in the one-story structure and larger than $0.002 \mathrm{FED} / \mathrm{s}$ in the two-story structure. However, the observed changes in FER values after different tactics was negligible compared to the changes observed in the heat exposure FER values after the same tactics. 
Water application reduced the FER values in all cases for both the one-story and two-story structures. On average, in the fire rooms, $60 \mathrm{~s}$ after water application, the FER values decreased by 1-2 orders of magnitude. In the non-fire rooms on the second floor of the two-story structure, the final FER values were less than $33 \%$ of the pre-water application values, and in the non-fire rooms on the first floor of both structures the final FER values were less than $20 \%$ of the pre-water application values.

It was observed that $60 \mathrm{~s}$ after every water application, the conditions in all of the non-fire rooms were below the firefighter tenability threshold for all straight stream water applications. However, for fog stream water applications, 3 out of the 22 non-fire rooms were above the temperature tenability threshold. The increased effectiveness of the straight stream water application was attributed to the cooling action of the two stream types and was characterized by a time-rate of change analysis in non-fire room temperatures.

While this study provides new insight into the impact of firefighting tactics on conditions that may be experienced by escaping occupants in residential structures, it is necessary to further quantify the repeatability and variability of fire growth and fire response to different tactics. Furthermore, additional tactical options can be considered for future study as well as the impact of different structural geometry and layout, particularly the location of ventilation openings with respect to the fire and suppression locations.

\section{Acknowledgments}

Funding was provided by the Department of Homeland Security (Grant No. EMW-2010-FP-00661).

\section{Open Access}

This article is distributed under the terms of the Creative Commons Attribution 4.0 International License (http://creativecommons.org/licenses/by/4.0/), which permits unrestricted use, distribution, and reproduction in any medium, provided you give appropriate credit to the original author(s) and the source, provide a link to the Creative Commons license, and indicate if changes were made.

\section{References}

1. Kerber S (2012) Analysis of changing residential fire dynamics and its implications on firefighter operational timeframes. Fire Technol 48(4):865-891

2. Svensson S (2000) "Fire Ventilation", Swedish Rescue Services Agency. Karlstad, Sweden. https://msb.se/RibData/Filer/pdf/20879.pdf

3. Ahrens M (2015) Home structure fires. NFPA, Quincy

4. Karter M, Molis JL (2010) U.S. firefighter injuries - 2009. NFPA, Quincy 
5. Fahy F, LeBlanc P, Molis J (2007) What's changed in the past 30 years. NFPA, Quincy

6. Karter M (2012) Fire loss in the United States during 2011. NFPA, Quincy

7. NIOSH (1998) Commercial structure fire claims the life of one fire fighter-California. NIOSH, Morgantown

8. NIOSH (2005) Career fire fighter dies and two career captains are injured while fighting night club arson fire-Texas. NIOSH, Morgantown

9. NIOSH (2008) A volunteer mutual aid captain and fire fighter die in a remodeled. NIOSH, Morgantown

10. NIOSH (2008) Volunteer fire fighter and trapped resident die and a volunteer lieutenant is injured following a duplex fire-Pennsylvania. NIOSH, Morgantown

11. NIOSH (2010) NIOSH alert: preventing deaths and injuries of fire fighters using risk management principles at structure fires. NIOSH, Morgantown

12. Kanterman R (2013) The suppression aggression olympics. Fire Engineering

13. Schwarz LG, Wheeler D(2009) Transitional fire attack. Fire engineering

14. Purchase D (2012) Offensive exterior operations, a new approach. Firefighternation. com

15. Layman L (1952) Attacking and Extinguishing Interior Fires. National Fire Protection Association, Boston

16. Svensson S, Särdqvist S (2001) Fire tests in a large hall, using manually applied highand low pressure water sprays. Fire Sci Technol 21(1):1-17

17. Kerber S (2013) Analysis of one and two-story single family home fire dynamics and the impact of firefighter horizontal ventilation. Fire Technol 49(4):857-889

18. ISO 13571 (2010) Life-threatening components of fire-guidelines for the estimation of time to compromised tenability in fires. ISO

19. Purser DA (2000) Toxic product yields and hazard assessment for fully enclosed design fires. Polym Int 49(10):1232-1255

20. Crewe RJ, Stec AA, Walker RG, Shaw JE, Hull TR, Rhodes J, Garcia-Sorribes T (2014) Experimental results of a residential house fire test on tenability: temperature, smoke, and gas analyses. J Forensic Sci 59(1):139-154

21. Guillaume E, Didieux F, Thiry A, Bellivier A (2014) Real-Scale fire tests of one bedroom apartments with regard to tenability assessment. Fire Saf J 70:81-97

22. Su JZ, Benichou N, Bwalya AC, Lougheed GD, Taber BC, Leroux P(2010) Tenability analysis for fire experiments conducted in a full-scale test house with basement fire scenarios. National Research Council of Canada

23. Kerber S(2012) Study of the effectiveness of fire service vertical ventilation and suppression tactics in single family homes. UL Firefighter Safety Research Institute, 2012. http://ulfirefightersafety.com/wp-content/uploads/2013/06/UL-FSRI-2010-DHS-Report_ Comp.pdf

24. Nakos JT (2004) Uncertainty analysis of thermocouple measurements in normal and abnormal thermal environment experiments at Sandia's radiant heat facility and Lurance Canyon Burn Site. Sandia National Laboratories, SAND2004-1023

25. Traina N, Kerber S, Kyritsis DC, Horn GP (2016) Occupant tenability in single family homes part I-impact of structure type, fire location and interior doors prior to fire department arrival. Fire Technology, Submitted

26. Standard on Protective Ensembles for Structural Fire Fighting and Proximity Fire Fighting (2007) National Fire Protection Association, NFPA 1971, 2007 Edition

27. Grant G, Brenton J, Drysdale D (2000) Fire suppression by water sprays. Progress Energy Combustion Sci 26(2):79-130 